\title{
Fetal surgery for occipital encephalocele
}

\author{
Sergio Cavalheiro, MD, PhD, ${ }^{1}$ Marcos Devanir Silva da Costa, MD, PhD, ${ }^{1}$ \\ Jardel Mendonça Nicácio, MD, ${ }^{1}$ Patricia Alessandra Dastoli, MD, PhD, ${ }^{1}$ \\ Italo Capraro Suriano, MD, PhD, ${ }^{1}$ Mauricio Mendes Barbosa, MD, PhD, ${ }^{2}$ \\ Hérbene Jose Milani, MD, ${ }^{2}$ Stéphanno Gomes Pereira Sarmento, MD, ${ }^{2}$ \\ Tereza Cristina Carbonari de Faria, PT, PhD, ${ }^{1}$ and Antonio Fernandes Moron, MD, PhD²
}

1'Department of Neurosurgery, Universidade Federal de São Paulo; and ²Department of Fetal Medicine, Hospital e Maternidade Santa Joana, São Paulo, Brazil

OBJECTIVE In this study, the authors retrospectively reviewed two cohorts of patients with occipital encephalocele $(\mathrm{OE})$ and demonstrate the technical aspects of an innovative and unprecedented method for fetal OE correction.

METHODS This was a cross-sectional retrospective study of 22 patients who underwent surgery from July 2012 to July 2018. The inclusion criteria for participants were a gestational age between 19 weeks and 27 weeks, a maternal age $\geq$ 18 years, a normal fetal karyotype, the presence of microcephaly, and a cystic hernial sac with the cystic component accounting for more than $80 \%$ of the total volume, which was larger than $10 \mathrm{ml}$. The fetuses with OE and microcephaly underwent intrauterine repair. The exclusion criteria were the presence of a fetal anomaly not associated with OE, chromosomopathy, presence of the brainstem inside the hernial sac or venous sinuses inside the herniated content, the risk of premature birth, placenta previa, and maternal conditions that would constitute an additional risk for fetal and maternal health, as well as refusal for fetal surgery. The authors reviewed the potential for microcephaly reversal and the longterm neurocognitive development.

RESULTS The authors report the cases of 9 fetuses with OE and microcephaly who underwent intrauterine OE repair at gestational ages of less than 27 weeks (fetal group). One case selected for fetal surgery also presented with placental abruption. All patients who underwent the fetal operation had microcephaly reversal, and 3 patients required ventriculoperitoneal shunting in the 1st year of life. The authors reviewed the cases of 12 patients who underwent postnatal repair. In 10 cases, fetal surgery was refused (postnatal group), and in 2 cases, the inclusion criteria for fetal surgery were not met. The authors evaluated the neurocognitive development of the patients with the Bayley Scales of Infant Development II. The median score for the fetal group was 98.7, and that for the postnatal group was 27.8.

CONCLUSIONS The intrauterine repair of OE may stop the progression of encephalocele sac herniation and result in microcephaly reversal. The fetal group had a better cognitive outcome than the postnatal group. The technique required to correct this defect is feasible for those with previous experience in the correction of fetal myelomeningocele. However, more studies are needed to ensure the efficacy of this procedure.

https://thejns.org/doi/abs/10.3171/2020.3.PEDS19613

KEYWORDS microcephaly; fetal surgery; occipital encephalocele; neural tube defects; congenital

$\mathrm{O}$ CCIPITAL encephalocele (OE) is a rare congenital neural tube defect characterized by a midline cranial bone opening that results in herniation of the meninges (meningocele) or of the meninges and brain tissue (encephalocele). The herniated neuronal tissue is usually healthy, which suggests that the bone cleft develops after the neurulation phase. ${ }^{1}$ Encephalocele has an estimated prevalence of $0.8-2.0$ per 10,000 live births, ${ }^{2-4}$ and
OE is the most prevalent form of this defect in Western countries, accounting for, in some series, up to $85 \%$ of the cases. $^{5-7}$

One of every three patients with OE dies, and the majority of these deaths occur in the 1st year of life. Of those who survive, $50 \%$ will experience some neurodevelopmental impairment or drug-resistant seizures. ${ }^{8,9}$ Hydrocephalus, the presence of intracranial abnormalities, the size of

ABBREVIATIONS MOMS = Management of Myelomeningocele Study; OE = occipital encephalocele; VP = ventriculoperitoneal . ACCOMPANYING EDITORIAL See pp 603-604. DOI: 10.3171/2020.5.PEDS20234.

SUBMITTED October 12, 2019. ACCEPTED March 30, 2020.

INCLUDE WHEN CITING Published online September 11, 2020; DOI: 10.3171/2020.3.PEDS19613. 
the herniated sac, the contents of the neural tissue in the herniated sac, microcephaly, and infection are some of the associated risk factors for death. ${ }^{6,8}$

Fetal ultrasound enables early diagnosis, with a detection rate of neural defects ranging from $60 \%$ to $94 \% .^{10,11}$ In addition, fetal MRI displays the anatomical details of the malformation, which confirms the ultrasound-based diagnoses and identifies possible associated anomalies. ${ }^{5,11}$ Moreover, the results of the Management of Myelomeningocele Study (MOMS), which support the efficacy of fetal surgery for myelomeningocele,,$^{12}$ encouraged our group to correct some cases of $\mathrm{OE}$, aiming to reduce the progression of microcephaly and neural tissue extrusion into the herniated sac. In this study, we retrospectively reviewed these cases and demonstrate the technical aspects of an innovative and unprecedented method for fetal OE correction.

\section{Methods \\ Patient Population}

This was a cross-sectional retrospective study approved by the research ethics committee of Universidade Federal de São Paulo. All patients' parents or guardians provided written institutional informed consent for the procedure and consented to their clinical data being used for research purposes.

The clinical, radiological, and surgical histories of patients were retrospectively reviewed to extract data regarding the neurological examinations and radiographic parameters. Between July 2012 and July 2018, 22 pregnant women whose fetuses presented with $\mathrm{OE}$ were evaluated at the Fetal Medicine Center.

The inclusion criteria were a gestational age between 19 weeks and 27 weeks, a maternal age $\geq 18$ years, a normal fetal karyotype, the presence of microcephaly (characterized as a head circumference below the 3rd percentile on ultrasound screening), and a cystic hernial sac with the cystic component accounting for more than $80 \%$ of the total volume, which was larger than $10 \mathrm{ml}$. The exclusion criteria were the presence of a fetal anomaly not associated with OE, chromosomopathy, the neural tissue component accounting for more than $20 \%$ of the total herniated volume, the presence of the brainstem inside the hernial sac, the presence of venous sinuses inside the herniated content, the risk of premature birth (including a short cervix and previous preterm delivery), placenta previa, and maternal conditions that would constitute an additional risk for fetal or maternal health (e.g., poorly controlled diabetes or hypertension, HIV, and hepatitis $\mathrm{B}$ or $\mathrm{C}$ positivity), as well as refusal for fetal surgery. All patients were screened with ultrasound and fetal MRI.

Ten patients were selected for intrauterine OE correction, and 12 were selected for postnatal OE repair. In 10 of these cases, the clinical criteria for fetal correction were met, but the family refused to allow the fetal surgery. Of the other 2 patients, one had Walker-Warburg syndrome, and the other showed brain tissue accounting for more than $20 \%$ of the encephalocele. The same neurosurgical team managed all patients in the postnatal and fetal repair groups.
The initial rationale for proposing intrauterine $\mathrm{OE}$ correction was the possibility of microcephaly and neural tissue herniation reversal. Therefore, neither patients with a large neural tissue herniation nor patients with a very small hernial sac that did not progress to microcephaly could benefit from fetal surgery (Fig. 1).

\section{Surgical Technique}

The surgical procedure took place in a regular operating room at a hospital dedicated to maternal and fetal medicine. The obstetrical steps of the surgical technique are similar to those proposed by Adzick et al. ${ }^{12}$ in the MOMS trial and modified by Moron et al. ${ }^{13}$

The neurosurgical steps start with the posterior region of the fetus's head positioned at the site of the uterine opening. In some cases, it was necessary to change the fetal position inside the womb. After exposure of the encephalocele through hysterotomy, a transillumination maneuver with the aid of a Xenon 3000 light was used to highlight the vasculature of the hernial sac. The correction of the OE began with microscopic magnification. A skin incision was made in the herniated sac; the sac was typically incised at the midline. Electric monopolar cautery was avoided; therefore, we typically used bipolar forceps at a very low intensity to attempt hemostasis when necessary. The meningeal tissue was then exposed and circumferentially dissected, followed by tissue coagulation with bipolar forceps and cutting with microscissors at the level of the outer table of the occipital bone. It was crucial to maintain a margin of safety from the meningeal layer to the posterior closure, and $2 \mathrm{~cm}$ was deemed sufficient. Next, the neural tissue was accessed, and the procedure was repeated; the vessels and tissues were coagulated and then excised to keep the neural tissue below the inner table of the occipital bone, or, when it was possible, the herniated neural tissue was relocated inside the skull. The meningeal layer was then closed with running 6-0 polypropylene sutures, and the skin flap was cut and reconstructed to avoid tissue overlap. The inner bone and dura mater were tethered to each other with 6-0 polypropylene, and an absorbable miniplate (LactoSorb) was used to reconstruct the parietooccipital cleft. This miniplate was placed between the inner table of the bone and the dura mater and fixed with 5-0 polypropylene stitches. Finally, the subcutaneous tissue was sutured with uncolored 5-0 polyglactin 910, and the skin was closed with running 6-0 poliglecaprone 25 sutures. After the correction of $\mathrm{OE}$, the fetus was released into the uterine cavity (Fig. 2).

Immediate postoperative care was provided in an obstetric intensive care unit, where the mothers remained for approximately 24 hours. Each mother was scheduled for elective cesarean delivery at 37 weeks of gestation or earlier in cases of obstetric indications, such as preterm labor, premature rupture of membranes, chorioamnionitis, placental abruption, and fetal distress, or in cases of suspected uterine dehiscence or rupture observed on ultrasound examination with a uterine scar thickness less than $2 \mathrm{~mm}$.

The delivery mode was transverse segmental cesarean section, which was performed through the surgical scar from the fetal surgery. In all procedures, the obstetrics team was assisted by a pediatric neurosurgeon to analyze 


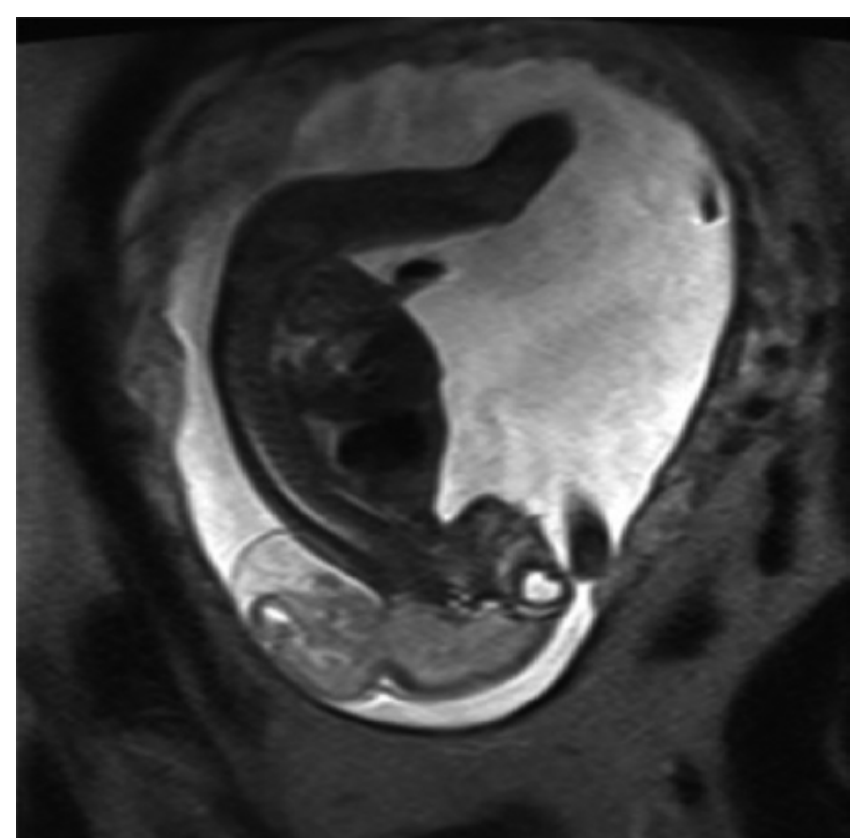

FIG. 1. Intrauterine MR image obtained in the case of a fetal OE that was contraindicated for fetal repair due to the high volume of neural tissue inside the hernial sac. the clinical condition of the newborn as well as to assess the surgical scar in the parietooccipital region.

The patients were followed by a multidisciplinary team composed of pediatricians, neurosurgeons, geneticists, physical therapists, and speech therapists every 2 months during the 1st year of life. Before the 3rd year of life, all patients were evaluated with the Bayley Scales of Infant Development II.

\section{Illustrative Cases \\ Case 1}

A 30-year-old pregnant woman presented to the Fetal Medicine Center with a fetus at 16 weeks of gestation; there was a single fetus with OE, and the woman did not have a history of previous gestation. She underwent investigation with fetal MRI and karyotyping by amniocentesis, which did not reveal other anomalies or chromosomopathy. By the time the fetus reached the gestational age of 24 weeks and 5 days, open fetal correction of the OE was performed; the procedure took a total of 135 minutes. The mother remained in the intensive care unit for 2 days, and after another 2 days in the hospital, she was discharged. At 33 weeks and 3 days of gestation, the mother presented with premature rupture of membranes, and a cesarean section was performed to deliver the neonate. The neonate had an Apgar score of 8 at 1 minute and 9 at 5 minutes,
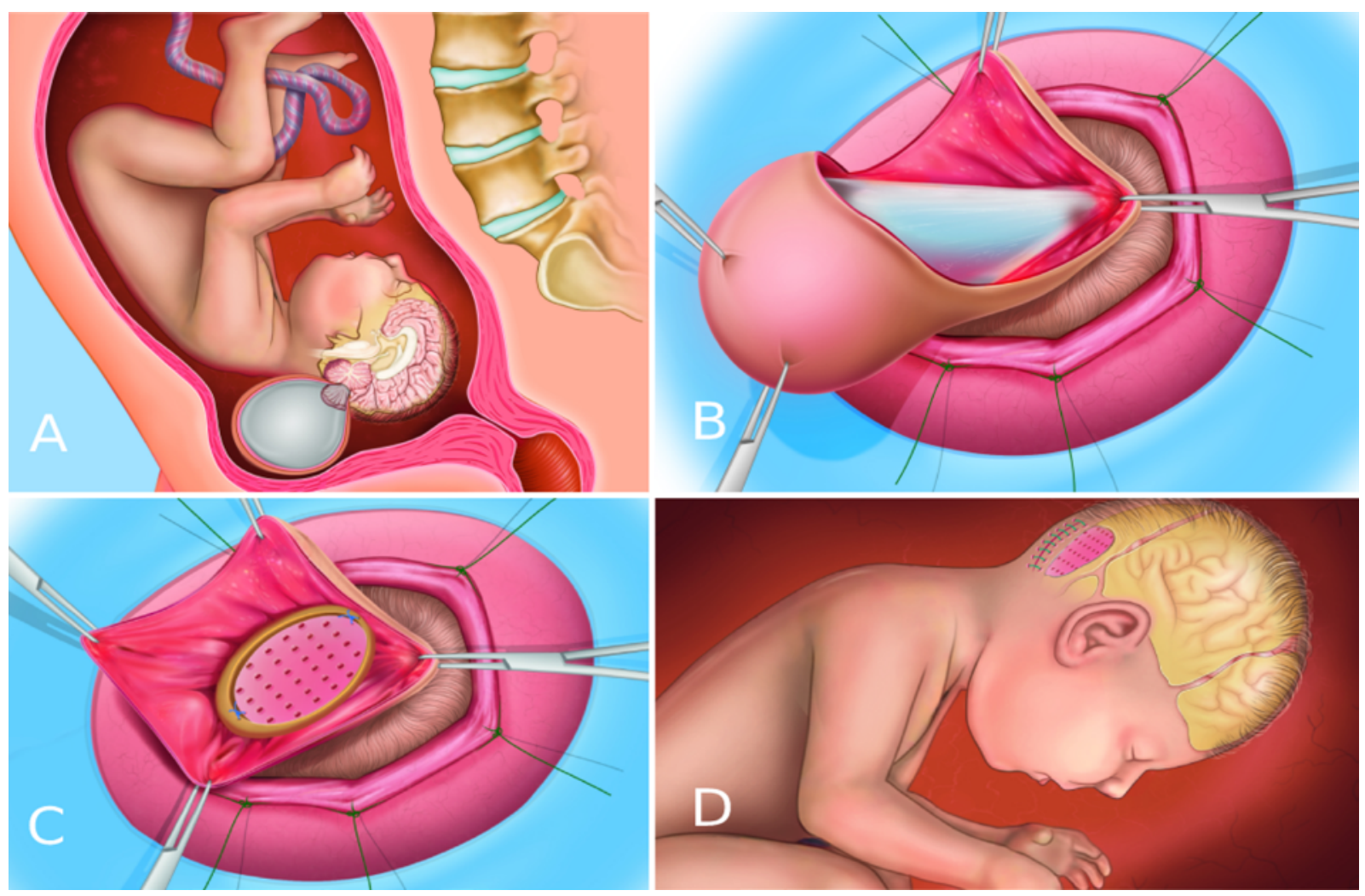

FIG. 2. Illustrations showing the main steps of fetal encephalocele repair using the open hysterotomy technique. A: Fetus in the womb cavity with an OE and microcephaly. B: Exposure of the encephalocele via hysterotomy and dissection of the meningeal layer. C: Placement of the absorbable miniplate to occlude the cranial cleft. D: Final aspect of the encephalocele correction, with the miniplate positioned and the normalization of cranial growth. Copyright Sergio Cavalheiro. Published with permission. 

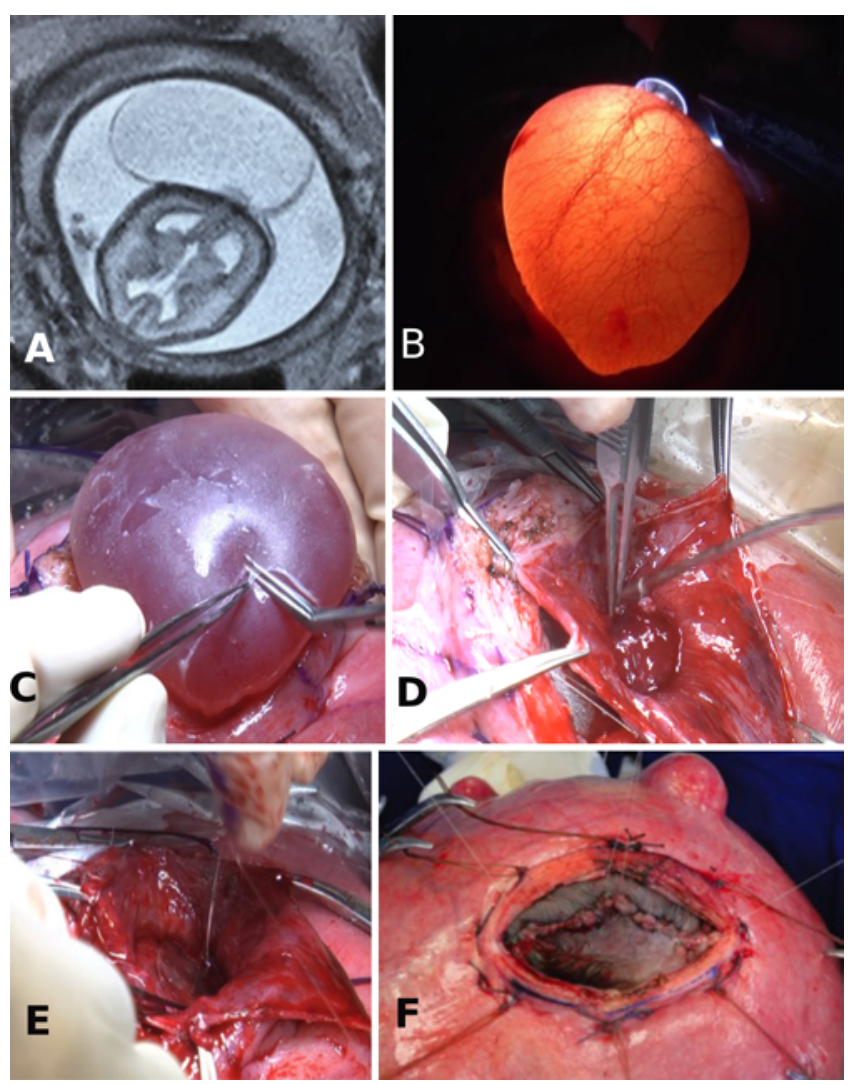

FIG. 3. Case 1. Images obtained at 24 weeks and 5 days in a male fetus who was found to have an OE of gestation. A: Fetal axial MR image of the brain showing a large OE and a small brain protrusion. B: Transillumination of the hernial sac, allowing the visualization of vessels in the encephalocele wall. C: Intraoperative exposure of the encephalocele through hysterotomy. D: Neural tissue manipulation and excision. E: Positioning of the absorbable plate to cover the bone defect. F: Final correction of the skin and a small myoma.

weighed $2290 \mathrm{~g}$, presented with respiratory distress syndrome, and remained in the neonatal intensive care unit for 3 weeks. At the age of 2 years, he attained a score of 105.4 on the Bayley Scales of Infant Development II. During the 6-year follow-up, he did not require ventriculoperitoneal (VP) shunting and did not have seizures (Fig. 3).

\section{Case 2}

A 30-year-old woman pregnant for the second time presented to the Fetal Medicine Center with a single fetus at 18 weeks of gestation with $\mathrm{OE}$ associated with unilateral ventriculomegaly. Her first pregnancy was unremarkable, and she had used folate for at least 3 months before the actual pregnancy. Fetal MRI at 21 weeks of gestation confirmed the ultrasound findings and revealed a hernial sac of $81.9 \mathrm{ml}$. Amniocentesis showed no chromosomal abnormalities or congenital infections. At a gestational age of 24 weeks and 4 days, the patient underwent fetal repair of the OE. During the surgical procedure, we could identify the communication between the hernial sac and the enlarged ventricle. The brain tissue removed showed gliosis and normal ependymal layers. We left a ventriculoamniotic shunt in the ventricle (Pudenz fixed, low-pres-
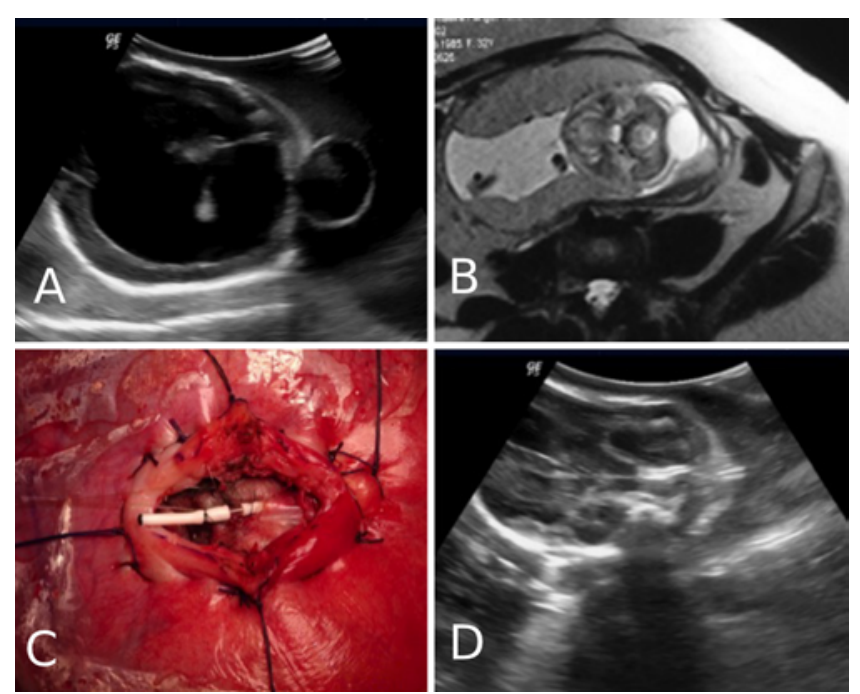

FIG. 4. Case 2. Images obtained at 18 weeks of gestation in a male fetus who was found to have an OE. A: Fetal sagittal ultrasound image showing an OE associated with ventriculomegaly. B: Fetal MR image showing the predominantly cystic OE. C: Ventriculoamniotic shunt is implanted in the fetus and fixed with nylon 5-0 sutures in the skin. D: Ultrasound image obtained on the 1st day postoperatively, revealing the absence of ventriculomegaly.

sure-type valve, Codman). Postoperative ultrasound and MRI revealed complete correction of the encephalocele and disappearance of the ventriculomegaly. The mother underwent cesarean section when the fetus reached a gestational age of 33 weeks and 6 days. The neonate was born in good condition, had Apgar scores of 7 and 9 at 1 and 5 minutes, respectively, and weighed $2500 \mathrm{~g}$. Just after birth, the ventriculoamniotic shunt was removed. Ultrasound on the 2nd day of life showed no hydrocephalus. On day 10 of life, the anterior fontanelle became tense and showed bulging, and ultrasonography showed ventriculomegaly; therefore, the patient underwent VP shunt placement (microprogrammable Codman Hakim shunt). The patient presented with moderately delayed cognitive and motor development, and at the age of 1 year, he showed a Bayley Psychomotor Development Index Score of 9.4 (Fig. 4).

\section{Results}

The maternal age ranged from 28 to 38 years old with a mean of 32.2 years. Among the mothers, 3 were in their first pregnancy, 5 were in their second pregnancy, and 2 were in their third pregnancy. One mother who was pregnant for the third time had experienced 2 previous spontaneous abortions. Of the 6 mothers who had given birth previously, only one had undergone a standard vaginal delivery, and all others had undergone delivery by cesarean section. The maternal BMI varied from 21.4 to $33.7 \mathrm{~kg} / \mathrm{m}^{2}$, and 4 mothers had taken folate supplements for at least 3 months after the beginning of gestation. Six mothers had an anterior insertion of the placenta in the womb. One of the 10 mothers suffered placental abruption just before hysterotomy, but the fetus was delivered and underwent postnatal correction of the $\mathrm{OE}$ after 48 hours of life; there- 
TABLE 1. Maternal features of patients undergoing intrauterine repair of an $O E$

\begin{tabular}{ccccccc}
\hline $\begin{array}{c}\text { Case } \\
\text { No. }\end{array}$ & $\begin{array}{c}\text { Maternal Age } \\
(\mathrm{yrs})\end{array}$ & $\begin{array}{c}\text { BMl } \\
\left(\mathrm{kg} / \mathrm{m}^{2}\right)\end{array}$ & $\begin{array}{c}\text { Previous } \\
\text { Cesarean Section }\end{array}$ & $\begin{array}{c}\text { Folate } \\
\text { Supplementation }\end{array}$ & $\begin{array}{c}\text { Placenta } \\
\text { Position }\end{array}$ & $\begin{array}{c}\text { Gestational Age at Op } \\
\text { (wks + days) }\end{array}$ \\
\hline 1 & 30 & 25.2 & No & No & Anterior & $24+5$ \\
\hline 2 & 30 & 26.4 & Yes & Yes & Anterior & $24+4$ \\
\hline 3 & 28 & 25.4 & Yes & Yes & Anterior & $24+2$ \\
\hline 4 & 34 & 22.3 & No & No & Anterior & $25+5$ \\
\hline 5 & 32 & 21.4 & Yes & Yes & Posterior & $25+6$ \\
\hline 6 & 32 & 26 & No & Yes & Anterior & 27 \\
\hline 7 & 32 & 22.9 & Yes & No & Posterior & 27 \\
\hline 8 & 38 & 25.2 & Yes & No & Anterior & $26+6$ \\
\hline 9 & 36 & 33.7 & Yes & No & Posterior & $25+5$ \\
\hline
\end{tabular}

fore, this case was excluded from the long-term analysis. The maternal features are summarized in Table 1 .

\section{Fetal Group}

We measured the volume of the OE hernial sac on the fetal MRI with iPlan/Elements/SmartBrush from Buzz Software (Brainlab); the volume ranged from 10.6 to $225.6 \mathrm{ml}$, and the median volume was $35.2 \mathrm{ml}$. All fetuses underwent correction before the gestational age of 27 weeks, and the median gestational age at correction was 25 weeks and 5 days, ranging from 22 weeks and 2 days to 27 weeks. The fetal head circumference was measured before surgery and after surgery every week until birth.

The fetal head circumference values were corrected for gestational age and analyzed using nonlinear regression statistics with exponential plateau curve fitting; then, they were compared with baseline data from the fetal head circumference curves of Snijders and Nicolaides. ${ }^{14}$ The head circumference before surgery revealed microcephaly; however, this trend was reverted after the fetal procedure (Fig. 5). Two fetuses showed ventriculomegaly at the time of the correction, and they underwent simultaneous ventriculoamniotic shunt insertion at the time of OE repair. In these 2 cases, we used a Pudenz fixed, low-pressuretype valve, and the ventricular catheter was inserted using a peel-away technique with a 5-Fr introducer (Cook). The ventriculoamniotic shunt was fixed to the skin with 5-0 nylon sutures (Fig. 4C).

All patients were delivered via cesarean section before the gestational age of 37 weeks; 3 were born before 32 weeks of gestation, and 6 were born between 32 and 37 weeks. The median gestational age at birth was 33 weeks and 3 days. Seven neonates were male. The median weight at birth was $2290 \mathrm{~g}$, ranging from $1180 \mathrm{~g}$ to $2800 \mathrm{~g}$. The main fetal morbidity was prematurity. The 3 patients born prior to 32 weeks required mechanical ventilation for an average of 8 days. Although all fetuses had their karyotypes studied via amniocentesis and the findings were normal, after birth, 1 patient presented with visual impairment associated with retinal detachment of the left eye and severe myopia of the right eye. Therefore, the possibility of Knobloch syndrome was suggested. The patient underwent genome sequencing, and a mutation was identified in the COL18A1 gene (c.12-2A $>\mathrm{T})$ in the long arm of chromo- some 21, which characterizes Knobloch syndrome (case 5 in Table 2). The tissue removed during OE correction was sent for pathological analysis, and in 8 fetuses, there was gliosis and vascular congestion; the results were normal in 1 fetus. Only 1 patient presented with seizures during the follow-up period.

The mean postnatal follow-up time was 2.25 years (range 1-6 years). Two patients who underwent ventriculoamniotic shunting required VP shunting in the 1st week after birth, and another patient required VP shunting during the follow-up period. We evaluated the neurocognitive development of the patients using the Bayley Scales of Infant Development II. For all 9 patients, the median score was $98.7 ; 7$ patients had scores higher than 90 points, and 2 had scores lower than 50 points, which is the minimum score on the scale, indicating severe developmental impairment. Of these 2 patients, one had Knobloch syndrome and presented with heterotopy and cerebellar vermis hypoplasia on postnatal brain MRI. All patients' features are displayed in Table 2.

\section{Postnatal Group}

We also obtained information from the 10 cases in which the patient was eligible for fetal correction of the $\mathrm{OE}$ but the family refused the procedure. This group had a median hernial sac volume of $36 \mathrm{ml}$ (range $20-50 \mathrm{ml}$ ), a median gestational age at birth of 38 weeks and 3 days (33 weeks to 39 weeks and 3 days), and a median birth weight of $2790 \mathrm{~g}(1750-3150 \mathrm{~g})$. This group also had a VP shunt rate of $20 \%$. The median Bayley Scales of Infant Development II score for this group was 27.8 (range 9-96.7). All clinical data are presented in Table 3. All patients were managed by the same neurosurgical team as the patients who underwent fetal correction.

\section{Group Comparison}

Although the number of patients was small, we compared the hernial sac volume, birth weight, Bayley Scales of Infant Development II score, and VP shunt status using the nonparametric Mann-Whitney U-test and considered $p<0.05$ to indicate a statistically significant difference. We found a significant difference in the median Bayley Scales of Infant Development II score between the postnatal group (27.8) and the fetal group (98.7) $(\mathrm{p}=0.03)$, 


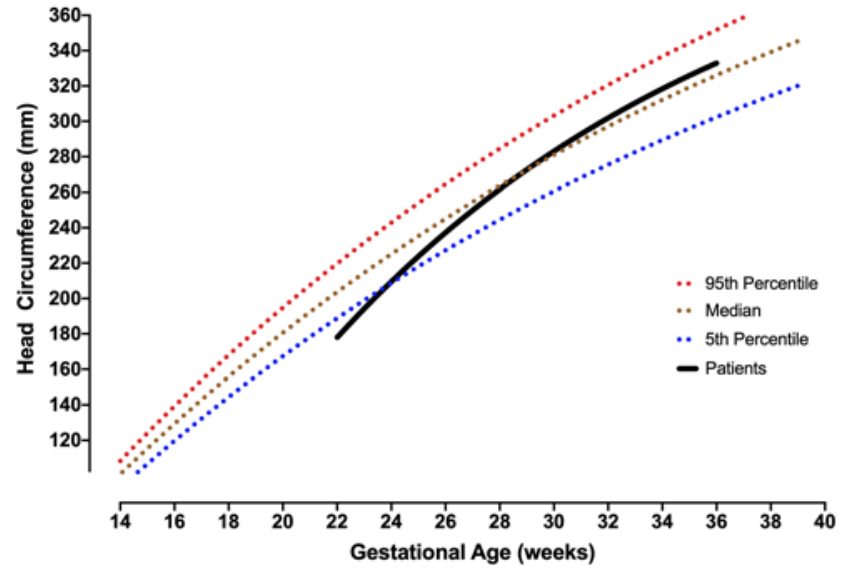

FIG. 5. Fetal head circumference fitted for gestational age derived from smoothed nonlinear regression statistics with exponential plateau curve fitting (black line), plotted with the median and 5th and 95th percentiles based on the fetal head circumference reference curves of Snijders and Nicolaides. ${ }^{14}$

as well as in the birth weight, with a median of $2790 \mathrm{~g}$ in the postnatal group and $2290 \mathrm{~g}$ in the fetal group $(\mathrm{p}=$ 0.02 ). However, there was no difference in the hernial sac volume, at $36 \mathrm{ml}$ in the postnatal group and $35.2 \mathrm{ml}$ in the fetal group $(p=0.704)$, or in the rate of VP shunting, at $33.3 \%$ in the fetal group and $20 \%$ in the postnatal group, by Fisher's exact test. However, there was a significant difference in prematurity between the groups; in the fetal and postnatal groups, $100 \%$ and only $10 \%$ of patients, respectively, were born before 37 weeks ( $p<0.001$, Fisher's exact test). No patients in the fetal or postnatal group required reoperation to repair the encephalocele.

\section{Discussion}

We observed that the fetal correction of OE reversed the trend toward microcephaly observed on preoperative ultrasound. Moreover, 7 of 9 patients had a score above 90 on the Bayley Scales of Infant Development II, which has a population mean \pm SD of $100 \pm 15$, representing an excellent neurocognitive outcome. Three of the 9 patients underwent VP shunting, and 2 exhibited ventriculomegaly before the fetal procedure.

The goal of this study was to review these cases and verify whether there was a reversal of microcephaly and a cessation of the herniation of nervous tissue after cranial dysraphism closure, especially in nonsyndromic cases. In all selected and treated patients, this reversal occurred. Although all patients underwent MRI, ultrasound, and fetal karyotyping, in one case, it was not possible to identify Knobloch syndrome. This difficulty in accurate prenatal diagnosis may be one of the determining factors affecting indications for fetal surgery.

OE may be associated with other anomalies in $20.5 \%$ to $60 \%$ of affected patients. Boyd et al. studied 670,766 deliveries in 11 European centers over 30 months and identified 542 cases of neural tube defects, including 58 cases of encephalocele; in $60 \%$ of these cases, encephalocele was not associated with other anomalies. ${ }^{10}$ In 21 cases, encephalocele was associated with other malformations (Meckel-Gruber syndrome in 5, amniotic bands in 3 , schizencephaly in 1, and multiple anomalies in 12). Other syndromes, such as Walker-Warburg, Joubert, and Knobloch syndromes, have also been described as being associated with OE..$^{1,10}$

Although fetal medicine has progressed, it is not possible to diagnose all types of fetal brain malformation, which can falsely compromise the result of fetal surgery. In case 5 , the patient was diagnosed with Knobloch syndrome just after birth using a genotyping microarray. This syndrome is a rare, recessively inherited disorder that manifests as visual impairment, severe myopia, recurrent retinal detachment, smooth irises, and persistent fetal vasculature and may also be associated with OE, bone defects, aplasia cutis, cerebellar vermis atrophy, polymicrogyria, subependymal nodules, and learning difficulties..$^{5-18}$ Our patient also presented with visual impairment, myopia, retinal de-

TABLE 2. Clinical data of patients who underwent fetal repair of an OE

\begin{tabular}{|c|c|c|c|c|c|c|c|c|c|c|}
\hline $\begin{array}{l}\text { Case } \\
\text { No. }\end{array}$ & Sex & $\begin{array}{l}\text { Presence } \\
\text { of Lemon } \\
\text { Sign }\end{array}$ & $\begin{array}{c}\text { Chromosome } \\
\text { Analysis }\end{array}$ & $\begin{array}{c}\text { Encephalocele } \\
\text { Sac Vol } \\
(\mathrm{ml})\end{array}$ & $\begin{array}{l}\text { Gestational } \\
\text { Age at Birth } \\
\text { (wks + days) }\end{array}$ & $\begin{array}{l}\text { Apgar } \\
\text { Score }^{*}\end{array}$ & $\begin{array}{l}\text { Weight } \\
\text { at Birth } \\
\text { (g) }\end{array}$ & $\begin{array}{l}\text { VP } \\
\text { Shunt }\end{array}$ & $\begin{array}{l}\text { Bayley Scales } \\
\text { of Infant } \\
\text { Development II }\end{array}$ & Seizure \\
\hline 1 & Male & Yes & Normal & 30 & $33+3$ & $8 / 9$ & 2290 & No & 105.4 & No \\
\hline 2 & Male & Yes & Normal & 81.9 & $33+6$ & $7 / 9$ & 2500 & Yes† & 9.4 & Yes \\
\hline 3 & Male & Yes & Normal & 35.2 & 30 & $7 / 8$ & 1180 & No & 90.9 & No \\
\hline 4 & Female & Yes & Normal & 70 & $30+5$ & $8 / 9$ & 1290 & No & 99.6 & No \\
\hline 5 & Male & No & c.12-2A>T mutation (COL18A1 gene) & 20.4 & $35+6$ & $9 / 10$ & 2580 & Yes† & 20.1 & No \\
\hline 6 & Male & Yes & Normal & 225.6 & $31+2$ & $9 / 10$ & 1510 & Yest & 98.7 & No \\
\hline 7 & Male & Yes & Normal & 120 & $32+6$ & & 2180 & No & 95.5 & No \\
\hline 8 & Female & Yes & Normal & 10.6 & $36+2$ & $8 / 10$ & 2715 & No & 108.1 & No \\
\hline 9 & Male & Yes & Normal & 26.3 & $34+3$ & $7 / 8$ & 2800 & No & 99.3 & No \\
\hline Median & & & & 35.2 & $33+3$ & $8 / 9$ & 2290 & & 98.7 & \\
\hline
\end{tabular}

* Presented as the score at 1 minute/5 minutes.

† These patients underwent VP shunt placement of a low-pressure distal slit valve. 
TABLE 3. Clinical data of patients who underwent postnatal repair of an OE

\begin{tabular}{|c|c|c|c|c|c|c|c|c|c|c|}
\hline $\begin{array}{l}\text { Case } \\
\text { No. }\end{array}$ & Sex & $\begin{array}{l}\text { Presence of } \\
\text { Lemon Sign }\end{array}$ & $\begin{array}{c}\text { Chromosome } \\
\text { Analysis }\end{array}$ & $\begin{array}{l}\text { Encephalocele } \\
\text { Sac Vol (ml) }\end{array}$ & $\begin{array}{l}\text { Gestational Age at } \\
\text { Birth (wks + days) }\end{array}$ & $\begin{array}{l}\text { Apgar } \\
\text { Score }^{*}\end{array}$ & $\begin{array}{l}\text { Weight at } \\
\text { Birth }(g)\end{array}$ & $\begin{array}{l}\text { VP } \\
\text { Shunt }\end{array}$ & $\begin{array}{c}\text { Bayley Scales of } \\
\text { Infant Development II }\end{array}$ & Seizure \\
\hline 1 & Male & Yes & Normal & 28 & $38+4$ & $8 / 9$ & 2830 & No & 20.8 & Yes \\
\hline 2 & Male & Yes & Normal & 40 & $37+3$ & $7 / 9$ & 2750 & No & 25.3 & Yes \\
\hline 3 & Female & Yes & Normal & 36 & $38+5$ & $9 / 10$ & 3020 & No & 96.7 & No \\
\hline 4 & Female & Yes & Normal & 50 & $39+2$ & $8 / 10$ & 2950 & No & 89.5 & No \\
\hline 5 & Female & No & Normal & 28 & $38+5$ & $7 / 9$ & 3150 & No & 53.8 & No \\
\hline 6 & Male & No & Normal & 39 & $39+3$ & $6 / 8$ & 2750 & Yes & 21.5 & No \\
\hline 7 & Male & Yes & Normal & 27 & $37+2$ & $6 / 9$ & 2450 & No & 30.3 & Yes \\
\hline 8 & Male & Yes & Normal & 20 & $38+1$ & $7 / 8$ & 2100 & Yes & 65.8 & No \\
\hline 9 & Male & Yes & Normal & 36 & 37 & $5 / 9$ & 2900 & No & 9 & Yes \\
\hline 10 & Female & Yes & Normal & 45 & 33 & $6 / 9$ & 1750 & No & 10 & No \\
\hline Median & & & & 36 & $38+3$ & $7 / 9$ & 2790 & & 27.8 & \\
\hline
\end{tabular}

* Presented as the score at 1 minute/5 minutes.

tachment, heterotopy, hypoplasia of the cerebellar vermis, subependymal nodules, and cognitive delay.

In the postoperative follow-up of the 9 patients, 2 presented with delayed neurodevelopment, which was severe in one case and moderate in the other. The patient with the severe delay exhibited hydrocephalus, seizures, and other chromosomal alterations that were not previously diagnosed. Careful prenatal evaluation can be used to select patients who will have a good outcome after fetal surgery.

Mahapatra $^{7}$ described a series of 13 patients with giant OE; 7 patients had hydrocephalus and required VP shunting, 2 patients died, 8 patients had microcephaly or associated craniostenosis, and 3 patients had a poor mental status during follow-up. In another series of cases, Kotil et al. ${ }^{19}$ reported on 12 patients with occipitocervical encephaloceles; among these patients, 7 presented with hydrocephalus, 4 exhibited neurological deficit and intellectual disability, and 4 died. One of the largest series, published by Kiymaz et al., ${ }^{8}$ described 30 patients, of whom 9 died, 18 had hydrocephalus, and 14 underwent VP shunting. OE is a severe disease that leads to considerable rates of mortality, hydrocephalus, microcephaly, and delayed neurodevelopment.

Technically, there is no great difficulty in repairing the $\mathrm{OE}$, especially in fetal neurosurgery centers. The use of transillumination allows the identification and localization of blood vessels in the cystic cavity, enabling proactive coagulation to avoid bleeding. In all cases, it was possible to close the OE. The placement of absorbable miniplates between the bone and the dura contributes to diminishing the pressure cone in the encephalocele and ceasing the herniation of the brain tissue. Except for the VP shunting that 2 patients required after birth, no other patient required further surgical procedures. There were no new cases of hydrocephalus after encephalocele closure. We experienced no cases of fetal or maternal mortality.

The advantage of this intrauterine surgery is that the defects in this period are smaller than those in the postnatal period, and the amount of herniated neural tissue is small, allowing for less-aggressive surgery with regard to the neural tissue. The presence of OE promotes intracrani- al hypotension, resulting in microcephaly. Kasprian et al. ${ }^{5}$ analyzed 14 cases of fetal $\mathrm{OE}$ and found signs of intracranial hypotension in 10 , the lemon sign in 6 , and decreased external CSF space in 4 . Of the 19 cases of repair in our study, the lemon sign was present on ultrasonography in 16 , suggesting intracranial hypotension. The restoration of intracranial pressure after OE correction prior to 27 weeks of gestational age restores normal skull growth.

Several surgical techniques have been described for the treatment of OEs after birth. Gallo ${ }^{20}$ proposed the placement of titanium mesh for the closure of giant OEs with subsequent enlargement of the skull and preservation of the herniated tissue. The use of absorbable miniplates between the inner table of the skull and the dura mater is simple and useful for covering larger bone defects. Zolal et al. ${ }^{21}$ described the use of diffusion tensor tractography on preoperative MRI to help delineate the position of the descending tracts and determine the best treatment method.

No intrauterine treatment of $\mathrm{OE}$ has been reported; before starting to operate on these patients, we hypothesized that fetal treatment would result in regression of the microcephaly and cessation of the extrusion of the neural tissue into the herniated sac. Based on our results, we observed the reversal of microcephaly. However, more time, cases, and studies are needed to obtain better information regarding the neurodevelopment of these patients.

\section{Conclusions}

The intrauterine repair of OE may stop the progression of encephalocele sac herniation and result in microcephaly reversal. However, open fetal surgery for encephalocele increases the risk for premature delivery. The technique required to correct this defect is feasible for those with previous experience in the correction of fetal myelomeningocele. However, more studies are needed to ensure the efficacy of this procedure.

\section{References}

1. Copp AJ, Stanier P, Greene ND. Neural tube defects: recent 
advances, unsolved questions, and controversies. Lancet Neurol. 2013;12(8):799-810.

2. Field B. Neural tube defects in New South Wales, Australia. $J$ Med Genet. 1978;15(5):329-338.

3. Kim K, Wang Y, Kirby RS, Druschel CM. Prevalence and trends of selected congenital malformations in New York State, 1983 to 2007. Birth Defects Res A Clin Mol Teratol. 2013;97(10):619-627.

4. Parker SE, Mai CT, Canfield MA, et al. Updated National Birth Prevalence estimates for selected birth defects in the United States, 2004-2006. Birth Defects Res A Clin Mol Teratol. 2010;88(12):1008-1016.

5. Kasprian GJ, Paldino MJ, Mehollin-Ray AR, et al. Prenatal imaging of occipital encephaloceles. Fetal Diagn Ther. 2015; 37(3):241-248.

6. Lo BW, Kulkarni AV, Rutka JT, et al. Clinical predictors of developmental outcome in patients with cephaloceles. $J \mathrm{Neu}$ rosurg Pediatr. 2008;2(4):254-257.

7. Mahapatra AK. Giant encephalocele: a study of 14 patients. Pediatr Neurosurg. 2011;47(6):406-411.

8. Kiymaz N, Yilmaz N, Demir I, Keskin S. Prognostic factors in patients with occipital encephalocele. Pediatr Neurosurg. 2010;46(1):6-11.

9. Siffel C, Wong LY, Olney RS, Correa A. Survival of infants diagnosed with encephalocele in Atlanta, 1979-98. Paediatr Perinat Epidemiol. 2003;17(1):40-48.

10. Boyd PA, Wellesley DG, De Walle HE, et al. Evaluation of the prenatal diagnosis of neural tube defects by fetal ultrasonographic examination in different centres across Europe. $J$ Med Screen. 2000;7(4):169-174.

11. Wilson RD, Audibert F, Brock JA, et al. Prenatal screening, diagnosis, and pregnancy management of fetal neural tube defects. J Obstet Gynaecol Can. 2014;36(10):927-939.

12. Adzick NS, Thom EA, Spong CY, et al. A randomized trial of prenatal versus postnatal repair of myelomeningocele. $N$ Engl J Med. 2011;364(11):993-1004.

13. Moron AF, Barbosa MM, Milani H, et al. Perinatal outcomes after open fetal surgery for myelomeningocele repair: a retrospective cohort study. BJOG. 2018;125(10):1280-1286.

14. Snijders RJ, Nicolaides KH. Fetal biometry at 14-40 weeks' gestation. Ultrasound Obstet Gynecol. 1994;4(1):34-48.

15. Caglayan AO, Baranoski JF, Aktar F, et al. Brain malformations associated with Knobloch syndrome-review of literature, expanding clinical spectrum, and identification of novel mutations. Pediatr Neurol. 2014;51(6):806-813.e8.
16. Hull S, Arno G, Ku CA, et al. Molecular and clinical findings in patients with Knobloch syndrome. JAMA Ophthalmol. 2016;134(7):753-762.

17. Khan AO, Aldahmesh MA, Mohamed JY, et al. The distinct ophthalmic phenotype of Knobloch syndrome in children. $\mathrm{Br}$ J Ophthalmol. 2012;96(6):890-895.

18. Kliemann SE, Waetge RT, Suzuki OT, et al. Evidence of neuronal migration disorders in Knobloch syndrome: clinical and molecular analysis of two novel families. Am J Med Genet A. 2003;119A(1):15-19.

19. Kotil K, Kilinc B, Bilge T. Diagnosis and management of large occipitocervical cephaloceles: a 10-year experience. Pediatr Neurosurg. 2008;44(3):193-198.

20. Gallo AE Jr. Repair of giant occipital encephaloceles with microcephaly secondary to massive brain herniation. Childs Nerv Syst. 1992;8(4):229-230.

21. Zolal A, Vachata P, Hejcl A, et al. Identification of the large descending tracts using diffusion tensor imaging in Chiari III malformation. Childs Nerv Syst. 2010;26(7):867-870.

\section{Disclosures}

The authors report no conflict of interest concerning the materials or methods used in this study or the findings specified in this paper.

\section{Author Contributions}

Conception and design: da Costa, Cavalheiro, Nicácio, Moron. Acquisition of data: da Costa, Cavalheiro, Nicácio, Faria. Analysis and interpretation of data: Cavalheiro. Drafting the article: da Costa, Cavalheiro. Critically revising the article: all authors. Reviewed submitted version of manuscript: all authors. Approved the final version of the manuscript on behalf of all authors: da Costa. Study supervision: Cavalheiro.

\section{Correspondence}

Marcos Devanir Silva da Costa: Universidade Federal de São Paulo,Brazil.marcoscostaneuro@gmail.com. 